\title{
Pengendalian biomassa giant salvinia (Salvinia molesta) dengan grass carp (Ctenopharyngodon idella)
}

\author{
R. N. Rahmi ${ }^{1}$, H. Effendi², M. M. Kamal ${ }^{1}$ \\ 1Departemen Manajemen Sumberdaya Perairan, Institut Pertanian Bogor, Bogor, Indonesia \\ ${ }^{2}$ Pusat Penelitian Lingkungan Hidup, Institut Pertanian Bogor, Bogor, Indonesia
}

\begin{abstract}
Abstrak
Penelitian dilaksanakan selama 28 hari di Pusat Penelitian Lingkungan Hidup Institut Pertanian Bogor (PPLH-IPB). Perlakuan terdiri dari ikan kecil (panjang total 7-12 cm) dengan kepadatan 5 dan 10 ikan/akuarium dan ikan besar (panjang total 21-24 cm) dengan kepadatan 2 dan 4 ekor/akuarium. Kiambang (Salvinia molesta) dengan biomassa awal 100 gram dimasukkan pada setiap akuarium untuk menutupi permukaan wadah sebesar $75 \%$. Hasil penelitian menunjukkan bahwa bobot tertinggi biomassa giant salvinia yang dikonsumsi sebesar $164,13 \pm 62,12$ gram terjadi pada perlakuan grass carp ukuran besar dengan padat tebar 4 ekor, yang diikuti dengan pertambahan bobot ikan rata-rata sebesar $6,63 \pm 6,51$ gram.
\end{abstract}

\begin{abstract}
.
The study was conducted for 28 days, at Environmental Research Center (ERC), IPB University. The treatments consisted of small fish (7-12 cm total length) with a density of 5 and 10 fishes/aquarium and large fish (total length of 21-24 cm) with densities of 2 and 4 fishes/aquarium. Salvinia molesta with an initial biomass of 100 grams was added to each aquarium to cover the surface of the container by $75 \%$. The results showed that the highest weight of giant Salvinia biomass consumed was $164.13 \pm 62.12$ gram occurred in large grass carp treatment with 4 fishes stocking density, followed by an average fish weight gain of $6.63 \pm 6.51 \mathrm{gram}$.
\end{abstract}

Keywords: salvinia, grass carp, weed, biomass

Kata kunci: salvinia, grass carp, gulma, biomassa

\section{PENDAHULUAN}

Ikan herbivor sering digunakan sebagai kontrol biologis untuk mengatasi gulma di perairan. Pemanfaatan grass carp (Ctenopharyngodon idella Val.) sebagai agen biokontrol untuk tumbuhan air tertentu telah banyak digunakan. Cara ini dapat menentukan tingkat konsumsi grass carp terhadap biomassa gulma air (Salvinia molesta) yang dijadikan objek makanan bagi ikan tersebut. Penggunaan kontrol biologis akan meminimalisir biaya dalam upaya penanganan pertumbuhan pesat (blooming) gulma air dibandingkan dengan cara pengambilan langsung. Selain itu, cara ini juga merupakan cara yang ramah lingkungan.

Grass carp banyak ditemukan di sungai-sungai besar di China, seperti Sungai Pearl, Sungai Qiantangjiang, Sungai Changjiang, Sungai Huiake dan ke utara sampai ke sistem Sungai Amur dan Sungai Heilongjiang (Mitchell 2009). Chilton and Muoneke (1992) mengemukakan bahwa popularitas penggunaan grass carp sebagai agen biokontrol tumbuhan air berkaitan dengan kemampuan dan daya tahan tubuhnya, mudah dibudidayakan, kontrol biologis yang efektif untuk berbagai tumbuhan air, serta sebagai sumber protein yang berkualitas tinggi. Faktor-faktor yang mempengaruhi tingkat kontrol vegetasi dengan grass

\footnotetext{
${ }^{*}$ Korespondensi Penulis

Email : rizkinovira@gmail.com
} 
carp adalah padat tebar ikan, iklim regional, serta kelimpahan dan komposisi spesies tumbuhan air (Garner et al. 2013; Silva et al. 2014).

Giant salvinia (Salvinia molesta Mitchell) adalah tanaman air yang memiliki kemampuan tumbuh pada perairan dengan nutrisi yang rendah dan memiliki pertumbuhan yang sangat cepat (Baki 1988). Giant salvinia merupakan tanaman yang sangat baik dalam meremediasi limbah organik dan anorganik, karena memiliki sifat hiperakumulator yang tinggi dan pertumbuhan yang sangat cepat (McFarland et al. 2004). Beberapa tumbuhan air memiliki epidermis dengan trikoma, berfungsi sebagai penghalang patogen dan mengeluarkan metabolit sekunder sebagai hasil sampingan dari pertahanan. Beberapa penelitian telah membuktikan bahwa trikoma dapat berperan dalam detoksifikasi logam berat (Lee et al. 2002).

Giant salvinia mampu berkembang dan memperbanyak populasinya sebanyak dua kali lipat dalam waktu satu minggu (Hartono et al. 2014). Namun di sisi lain, pertumbuhan yang cepat dari vegetasi ini menjadikannya termasuk sebagai gulma air yang merugikan, karena menyebabkan tertutupnya permukaan perairan. Hal tersebut akan mendorong terjadinya pendangkalan pada perairan dan mengurangi intensitas sinar matahari yang masuk ke perairan, sehingga konsentrasi oksigen terlarut di perairan akan mengalami penurunan. Selain itu, kemampuan tumbuhan ini dalam menggandakan dirinya dengan sangat cepat juga menimbulkan hal negatif, karena dapat menggantikan tanaman air asli pada danau seperti ganggang (Hydrilla). Berdasarkan hal tersebut, penelitian ini berfokus untuk mengetahui bagaimana tingkat konsumsi grass carp (Ctenopharyngodon idella Val.) terhadap tumbuhan air giant salvinia (Salvinia molesta Mitchell).

\section{METODOLOGI}

Penelitian ini dilaksanakan selama 28 hari di Pusat Penelitian Lingkungan Hidup-Institut Pertanian Bogor (PPLH-IPB). Penelitian dilakukan dalam dua tahap dengan mengacu pada Kasinak et al. (2015) meliputi :

1) Persiapan \& perancangan wadah untuk menumbuhkan tanaman air giant salvinia (Salvinia molesta Mitchell) dan pemeliharaan grass carp (Ctenopharyngodon idella Val.) sebagai biokontrol. Sebanyak 12 akuarium dengan volume air 75 liter disiapkan sebagai wadah dalam penelitian.

2) Pengujian tingkat konsumsi ikan grass carp terhadap giant salvinia sebagai pakan alaminya. Perlakuan dalam pengujian berupa ukuran ikan kecil (panjang total 7-12 cm) dengan padat tebar 5 dan 10 ekor dan ukuran besar (panjang total 21-24 cm) dengan padat tebar 2 dan 4 ekor dengan masingmasing perlakuan dilakukan sebanyak 3 kali ulangan. 
Giant salvinia dan grass carp terlebih dahulu dilakukan proses aklimatisasi selama 3 hingga 5 hari. Pemeliharaan grass carp dilakukan di dalam wadah yang dipersiapkan dengan air yang telah diaerasi selama 2-3 hari agar tersedia oksigen dalam air dan pemasangan heater untuk mengatur suhu air agar tetap stabil $\left(27-30^{\circ} \mathrm{C}\right)$, agar grass carp dan kiambang dapat tumbuh dengan baik. Peralihan pakan dilakukan bertahap dari eceng gondok yang semula sebagai makanan utama menjadi giant salvinia, dengan menyisipkan giant salvinia sebagai makanan baru. Bila ikan mulai mengonsumsi giant salvinia, artinya grass carp telah menyesuaikan diri dengan giant salvinia sebagai makanan utamanya.

Percobaan dilakukan terhadap ikan yang telah dipuasakan selama 2 hingga 3 hari. Menurut Kasinak et al. (2015), ikan yang dipuasakan sebelum dilakukan penelitian dimaksudkan untuk meningkatkan rasa lapar dan meningkatkan nafsu makan, agar tingkat konsumsi terhadap giant salvinia bisa optimal. Perawatan akuarium, seperti penyifonan dan penambahan air dilakukan secara rutin setiap harinya untuk mengembalikan volume air agar selalu 75 liter.

Giant salvinia (Salvinia molesta) ditanam pada media yang telah disediakan dengan biomassa awal sebesar 100 gram pada setiap akuarium untuk menutupi permukaan wadah sebesar 75\% (Gambar 1). Sebagai perlakuan, ditebarkan grass carp dengan jumlah yang berbeda pada setiap akuarium yakni padat tebar 5 dan 10 untuk ikan ukuran kecil dengan masing-masing 3 kali ulangan dan padat tebar 2 dan 4 ekor untuk ikan ukuran besar pada masing-masing wadah dengan umur ikan di atas 3 minggu. Hal ini berdasarkan pada Cudmore and Mandrak (2004) yang menyatakan bahwa pada minggu ke tiga, grass carp mulai memakan tanaman. Pemeliharaan dilakukan dengan pengontrolan faktor yang dapat menjadi stresor bagi ikan yang dipelihara tanpa pemberian pakan tambahan dari aspek ukuran dan padat tebar.

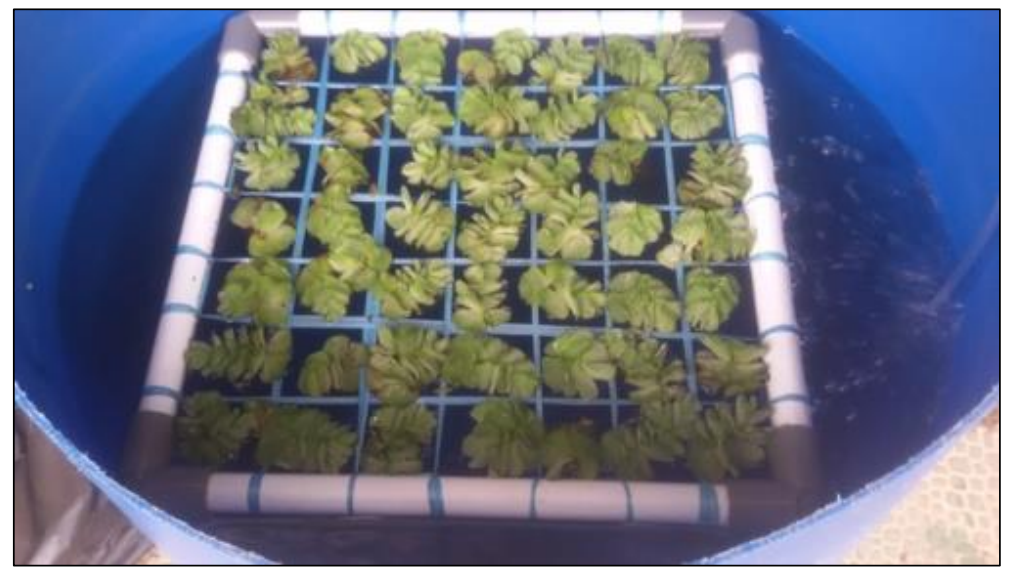

Gambar 1. Giant salvinia yang menutupi sekitar 75\% akuarium. 


\section{HASIL DAN PEMBAHASAN}

Air yang digunakan merupakan air yang telah diaerasi selama 3 hari dengan suhu $27-30^{\circ} \mathrm{C}$. Pada sistem pemeliharaan, suhu sangat berpengaruh terhadap kemampuan makan grass carp dalam mengonsumsi giant salvinia (Yang et al. 2016).

\subsection{Tingkat konsumsi giant salvinia oleh grass carp}

Grass carp banyak dimanfaatkan sebagai agen kontrol biologi dari vegetasi air karena grass carp memiliki usus yang lebih pendek dibandingkan dengan ikan herbivor lainnya. Usus pendeknya memiliki waktu retensi kurang dari 8 jam dan pengurangan efisiensi pencernaan $60-70 \%$. Karena pengurangan efisiensi pencernaannya, grass carp mengonsumsi banyak vegetasi (Masser 2002).

Silva et al. (2014) menggunakan grass carp dalam penelitiannya sebagai agen kontrol biologi terhadap beberapa makrofita air di Brazil, diantaranya Ceratophyllum Demersum, Egeria densa dan Egeria najas. Hasil yang ditunjukkan dalam penggunaan grass carp terhadap preferensi pakan pada makrofita tersebut secara berturut-turut yaitu $C$. demersum sebagai preferensi pakan tertinggi, selanjutnya adalah E. najas dan E. densa.

Selama 28 hari pemeliharaan, grass carp mengonsumsi giant salvinia dengan kemampuan yang berbeda untuk setiap ukuran dan jumlah padat tebar (Tabel 1). Berdasarkan hasil yang diperoleh, giant salvinia yang dikonsumsi oleh grass carp berukuran besar dengan padat tebar 4 yaitu 164,13 $\pm 62,12$ gram, dengan penambahan giant salvinia sebanyak $100 \pm 0,0$ gram selain perlakuan semula. Penambahan giant salvinia ini dilakukan karena giant salvinia telah habis dikonsumsi sebelum 28 hari. Sementara itu, ikan besar dengan padat tebar 2 ekor dapat menghabiskan giant salvinia sebanyak 94,77 $\pm 4,58$ gram. Grass carp ukuran kecil dengan padat tebar 10 ekor mengonsumsi giant salvinia sebanyak $87,00 \pm 1,73$ gram. Grass carp ukuran kecil dengan padat tebar 5 ekor mengonsumsi giant salvinia sebanyak $56,77 \pm 7,12$ gram.

Tabel 1. Tingkat konsumsi grass carp terhadap giant salvinia selama 28 hari.

\begin{tabular}{ccccc}
\hline \multirow{2}{*}{ Perlakuan } & \multicolumn{4}{c}{ Bobot giant salvinia (gram) } \\
\cline { 2 - 5 } & $\mathrm{t}_{0}$ & $\begin{array}{c}\text { Penambahan } \\
\text { giant salvinia }\end{array}$ & $\mathrm{T}_{28}$ & $\begin{array}{c}\text { Jumlah yang } \\
\text { dikonsumsi grass carp }\end{array}$ \\
\hline 4 ekor ikan besar & $100 \pm 0,0$ & $100 \pm 0,0$ & $2,53 \pm 4,39$ & $-164,13 \pm 62,12$ \\
2 ekor ikan besar & $100 \pm 0,0$ & $0,0 \pm 0,0$ & $5,23 \pm 4,59$ & $-94,77 \pm 4,58$ \\
10 ekor ikan kecil & $100 \pm 0,0$ & $0,0 \pm 0,0$ & $13,00 \pm 1,73$ & $-87,00 \pm 1,73$ \\
5 ekor ikan kecil & $100 \pm 0,0$ & $0,0 \pm 0,0$ & $43,23 \pm 7,12$ & $-56,77 \pm 7,12$ \\
\hline
\end{tabular}

Giant salvinia bertahan pada suhu ekstrem $\left(3-43^{\circ} \mathrm{C}\right)$ dan optimum pada suhu $24-28^{\circ} \mathrm{C}$. Disamping itu, suhu optimum tingkat konsumsi grass carp antara $21^{\circ} \mathrm{C}$ hingga $30^{\circ} \mathrm{C}$ (Masser 2002). Namun, pada suhu optimum yang diterapkan 
dalam sistem pemeliharaan $\left(27-30^{\circ} \mathrm{C}\right)$ diperoleh hasil bahwa kemampuan makan grass carp lebih optimum dibandingkan dengan kemampuan tumbuh giant salvinia.

Hal yang sama terjadi pada penelitian yang dilakukan oleh McIntosh et al. (2003) yang meneliti kemampuan makan tilapia terhadap giant salvinia. Hasil yang diperoleh berupa konsumsi giant salvinia sebesar 491 $\pm 117,4$ gram dengan biomassa awal 380 $\pm 0,0$ gram dan penambahan sebesar $228 \pm 208,1$ gram. Grass carp dan tilapia sebelumnya telah diperkenalkan di beberapa perairan sepanjang Sungai Colorado yang dipenuhi oleh vegetasi giant salvinia dan dapat berkontribusi sebagai agen kontrol biologi gulma invasif ini.

\subsection{Perubahan bobot grass carp akibat aktivitas pakan}

Perubahan bobot grass carp ukuran besar dengan padat tebar 4 ekor selama 28 hari mengonsumsi giant salvinia adalah peningkatan bobot rata-rata sebesar 6,63 $\pm 6,51$ gram. Hal yang sama terjadi pada perlakuan ikan kecil dengan padat tebar 10 ekor, dengan peningkatan bobot rata-rata sebesar 0,79 $\pm 0,63$ gram. Berbeda halnya yang terjadi pada ikan besar dengan padat tebar 2 ekor dan perlakuan ikan kecil dengan padat tebar 5 ekor, yang terjadi adalah penurunan pada bobot ikan. Penurunan yang terjadi secara berturut-turut adalah sebesar 2,05 $\pm 17,03$ gram dan 0,21 $\pm 0,95$ gram. Perubahan-perubahan yang terjadi pada bobot grass carp selama 28 hari pemeliharaan untuk setiap perlakuan padat tebar berbeda disajikan melalui Tabel 2.

Tabel 2. Perubahan bobot rata-rata grass carp setelah 28 hari.

\begin{tabular}{cccc}
\hline \multirow{2}{*}{ Perlakuan } & \multicolumn{3}{c}{ Bobot grass carp (gram) } \\
\cline { 2 - 4 } & $\mathrm{t}_{0}$ & $\mathrm{~T}_{28}$ & Perubahan \\
\hline 4 ekor ikan besar & $111,78 \pm 4,81$ & $118,41 \pm 10,35$ & $6,63 \pm 6,51$ \\
2 ekor ikan besar & $103,68 \pm 14,95$ & $101,30 \pm 13,59$ & $-2,05 \pm 17,03$ \\
10 ekor ikan kecil & $12,91 \pm 1,22$ & $12,60 \pm 1,02$ & $0,79 \pm 0,63$ \\
5 ekor ikan kecil & $13,38 \pm 1,66$ & $11,21 \pm 1,53$ & $-0,21 \pm 0,95$ \\
\hline
\end{tabular}

Penurunan bobot yang terjadi pada grass carp diduga akibat adanya penurunan nafsu makan ikan selama pemeliharaan. Hal ini didukung oleh Rahardjo et al. (2011), bahwa ikan tidak mengonsumsi pakan sepanjang hari, melainkan pada waktu tertentu yang berhubungan dengan kepenuhan lambung. Selain itu diduga pula terjadi akibat tidak adanya pilihan makanan, yang artinya giant salvinia merupakan satu-satunya sumber makanan untuk grass carp. Penurunan bobot terjadi pula pada ikan nila dalam penelitian McIntosh et al. (2003), dijelaskan bahwa hal ini karena kurangnya manfaat gizi yang diberikan giant salvinia kepada ikan. 


\section{KESIMPULAN DAN SARAN}

Penurunan tertinggi biomassa giant salvinia terjadi pada perlakuan grass carp berukuran besar dengan padat tebar 4 ekor. Penurunan yang terjadi sebesar $164,13 \pm 62,12$ gram, yang juga diikuti dengan pertambahan bobot ratarata grass carp sebesar 6,63 $\pm 6,51$ gram.

\section{UCAPAN TERIMAKASIH}

Syukur kepada Allah SWT dan terima kasih kepada Pusat Penelitian dan Lingkungan Hidup, Institut Pertanian Bogor (PPLH-IPB).

\section{DAFTAR PUSTAKA}

Baki BB. 1988. Salvinia molesta Mitchell-biology and prospects of biological control with Cyrtobagous salviniae calder \& sands in Malaysia. Central Research Laboratories. Selangor.

Chilton EW and Muoneke MI. 1992. Biology and management of grass carp (Ctenopharyngodon idella, Cyprinidae) for vegetation control : a North American perspective. Rev Fish Biol Fisheries 2(1992):283-320.

Cudmore B and Mandrak NE. 2004. Biological synopsis of grass carp (Ctenopharyngodon idella). Canadian Manuscript Report of Fisheries and Aquatic Sciences 2705:1-44.

Garner AB, Kwak TJ, Manuel KL and Barwick DH. 2013. High-density grass carp stocking effect on a reservoir invasive plant and water quality. J. Aquat. Plant Manage. 51:27-33.

Hartono JSS, Same M dan Parapasan Y. 2014. Peningkatan mutu kompos kiambang melalui aplikasi teknologi hayati dan kotoran ternak sapi. Jurnal Penelitian Pertanian Terapan 14(1):196-202.

Kasinak JE, Bishop CJ, Wright RA and Wilson AE. 2015. Grass carp do not consume the nuisance benthic cyanobacterium, Lyngbya wollei. J. Aquat Plant Manage. 53:74-80.

Lee S, Moon JS, Domier LL and Korban SS. 2002. Molecular characterization of phytochelatin synthase expression in transgenic Arabidopsis. Plant Physiology and Biochemistry 40(9):727-733.

Masser MP. 2002. Using grass carp in aquaculture and private impoundments. Southern Regional Aquaculture Center. Texas.

McFarland DG, Nelson LS and Grodowitz MJ. 2004. Salvinia molesta D.S. Mitchell (giant salvinia) in the United States: a review of species ecology and approaches to management. Aquatic Plant Control Research Program (APCRP), U.S. Army Engineer Research and Development Center (ERDC). Vicksburg. 
McIntosh D, King C and Fitzsimmons K. 2003. Tilapia for biological control of Giant Salvinia. J. Aquat. Plant Manage. 41:28-31.

Mitchell CP. 2009. Profile of white amur and silver amur from the results of releases in New Zealand. Raglan: Charles Mitchell and Associates Biological Consultants. New Zealand.

Rahardjo MF, Sjafei DS, Affandi R dan Sulistiono. 2011. Iktiology. Lubuk Agung. Bandung.

Silva AF, Cruz C, Pitelli RLCM and Pitelli RA. 2014. Use of grass carp (Ctenopharyngodon idella) as a biological control agent for submerged macrophytes. Planta Daninha 32(4):765-773.

Yang Y, Yu H, Li H, Wang A and Yu HY. 2016. Effect of high temperature on immune response of grass carp (Ctenopharyngodon idellus) by transcriptome analysis. Fish \& Shellfish Immunolog 58(2016):89-95. 